\title{
CONDIÇÃO HIGIÊNICO - SANITÁRIA DE ABATEDOURO FRIGORÍFICO E FÁBRICA DE EMBUTIDOS NO ESTADO DO PARANÁ
}

\section{HYGIENIC AND SANITARY CONDITION OF A REFRIGERATOR SLAUGHTERHOUSE AND BUILT FACTORY IN PARANÁ STATE}

\author{
Renata Louize Samulak ${ }^{1}$; Giovana Fanchin Zanetti ${ }^{2}$; Sabrina Ávila Rodrigues ${ }^{3}$ Juliana Vitória Messias \\ Bittencourt $^{4}$ \\ ${ }^{1,3,4}$ Universidade Tecnológica Federal do Paraná - UTFPR - Ponta Grossa - Brasil \\ renatasamulak@hotmail.com; sabrinaqa2003@yahoo.com.br; julianavitoria@utfpr.edu.br \\ ${ }^{2}$ Universidade Federal do Paraná - UFPR - Curitiba - Brasil \\ giovanazanetti@yahoo.com.br
}

\begin{abstract}
Resumo
Produtos cárneos são potentes veiculadores de bactérias patogênicas, desta forma torna-se importante que todo o processo de produção seja monitorado para assegurar a qualidade microbiológica do produto final. O presente trabalho objetivou verificar a condição higiênico sanitária de um abatedouro frigorífico e fábrica de embutidos no estado do Paraná. Com este propósito, foram avaliadas pelo método swab amostras de três carcaças suínas na região do lombo nas etapas de pré abate; após depilação e evisceração e antes e pós lavagem, sendo as três últimas coletadas da área interna e externa da carcaça. Para avaliação das condições de higiene do ambiente foram coletadas amostras da parede da área de sangria, depiladeira, mesa de evisceração, mesa de fabricação de embutidos e $50 \mathrm{ml}$ de água do tanque de escaldagem. Também foram coletadas amostras de mãos de dois manipuladores os quais trabalham na fabricação e $100 \mathrm{~g}$ de dois embutidos, sendo um cozido e um cru. Os materiais coletados foram transportados $e$ analisados no Laboratório de Microbiologia da UTFPR, onde foi feita a determinação do número mais provável (NMP) de coliformes totais, fecais (Escherichia coli), contagem padrão de microrganismos aeróbios mesófilos, estritos ou facultativos viáveis, contagem de Staphylococcus spp e avaliação da presença de Salmonella spp. Algumas amostras avaliadas apresentaram contaminação por coliformes fecais, totais, mesófilos, Salmonella e Staphylococcus, porém o grau de contaminação para a maioria das amostras manteve-se dentro dos limites estabelecidos pela legislação.
\end{abstract}

Palavras-chave: contaminação; carcaça suína; higiene.

\section{`1 Introdução}

O Brasil tem ocupado papel de destaque no mercado mundial como importante produtor de alimentos, demonstrando significativo potencial de produção e exportação de alimentos de origem animal, dentre eles a carne suína. 
De acordo com a Associação Brasileira da Indústria Produtora e Exportadora de Carne Suína (Abipecs), a região sul do Brasil concentra os três maiores produtores de carne suína do país, com o estado do Paraná ocupando o terceiro lugar. Com relação ao mercado externo, de janeiro a abril de 2011, os principais destinos da carne suína brasileira foram a Rússia e a China (ABIPECS, 2011).

Diante da globalização e da crescente conscientização dos consumidores em procurar alimentos com qualidade microbiológica, toda a cadeia produtiva deverá estar preparada para o desafio de produzir alimentos seguros, com excelência de qualidade (BEZZERA e MARTINS, 2008).

O aumento da produção de alimentos gera uma preocupação inevitável com a segurança alimentar, uma vez que os alimentos podem ser veiculadores de doenças representando um risco à saúde pública. Nesse sentido, o país necessita de maior dedicação com relação ao aspecto da saúde do rebanho nacional, garantindo a transformação do animal em carne com excelência de qualidade.

Os alimentos de diferentes origens e naturezas são capazes de veicular agentes patogênicos, especialmente quando sua cadeia produtiva não mantém rigorosa higiene e medidas preventivas de contaminação. Os alimentos mais freqüentemente envolvidos em doenças transmitidas por alimentos (DTA's) são os de origem animal, sendo que as carnes ocupam o segundo lugar (OMS, 2002).

Carmo et al. (2005) obtiveram dados do Sistema de Informações Hospitalares (SIH) do Ministério da Saúde, e foi verificado que ocorreram mais de 3.400.000 internações por Doenças transmitidas por alimentos (DTA’s) no Brasil, de 1999 a 2004, com uma média de cerca de 570 mil casos por ano.

O envolvimento de carnes e produtos cárneos na ocorrência de DTA's se dá pelo fato de que muitos agentes patogênicos pertencem a microbiota natural dos animais de corte (trato digestório, faringe, tonsilas, narinas, tecido linfático) e contaminando as carcaças durante o abate. Estes agentes também são transportados do ambiente contaminado para as carcaças pelo manipulador, utensílios, alimentos e pela água (MATSUBARA, 2005).

Para Lima e Sousa (2002), a microbiota de um alimento é composta por microrganismos associados à matéria-prima, por contaminantes adquiridos durante as etapas de processamento através da água, das instalações ou equipamentos. Um alimento está sujeito à contaminação diversas origens, porém é possível realizar um controle para manter a microbiota em um número aceitável que não cause problemas de saúde pública.

Produtos de origem animal possuem uma variedade de microrganismos presentes naturalmente ou adquiridos durante o abate. Alguns podem se multiplicar na carne causando 
deterioração e redução da vida de prateleira, outros representam um perigo à saúde dos consumidores por serem causas de intoxicações, doenças infecciosas ou toxinfecciosas (ICMSF, 1997; CORTEZ, 2003).

De acordo com Borch et al. (1996), os animais são os principais geradores da carga microbiana, a partir do conteúdo gastrointestinal, pele, pêlos, região orofaríngea, além dos operadores do ambiente. No processo de abate não há nenhum ponto onde os perigos possam ser eliminados completamente, porém há possibilidade de diminuir a carga microbiana mediante a utilização de Boas Práticas de manejo pré-abate, limpeza e desinfecção de instalações, equipamentos e ambiente de abate, constante treinamento sobre higiene de manipuladores e procedimentos operacionais de abate, utilização de práticas preventivas como Boas Práticas de Fabricação e Procedimentos Operacionais Padronizados.

Para Marra (2009) a carne serve como substrato para a multiplicação de microrganismos devido seu alto valor biológico e sua composição química. As etapas anteriores à sua comercialização, quando realizadas inadequadamente, podem se transformar em fontes de contaminação comprometendo a qualidade do produto final.

O número e o tipo de microrganismos presentes na carne refletem as condições higiênicosanitárias do abatedouro bem como as de armazenamento após o abate o que define também a vida de prateleira da carcaça. (HUGAS, 1998; MARRA, 2009).

As bactérias aeróbias mesófilas constituem a maioria dos microorganismos acidificantes responsáveis pela deterioração dos alimentos. Para Capita et al.(1999), os mesófilos não apresentam risco potencial a saúde humana, mesmo que muitas bactérias patogênicas sejam mesófilas. O elevado número desses microorganismos está diretamente relacionada a condições higiênicosanitárias desfavoráveis.

A Salmonella é uma das bactérias que mais causam toxiinfecções de origem alimentar em seres humanos. De acordo com Bessa et al.(2004) os suínos são portadores de Salmonella em linfonodos e trato digestivo, tornando as fezes e linfonodos mesentéricos importantes fontes de contaminação de carcaças no abatedouro. Para Seixas et al. (2009), para controlar o crescimento de Salmonella em suínos é imprescindível identificar os períodos em que o animal é contaminado, os fatores que levam a multiplicação desse patógeno e as condições em que se pode ocorrer contaminação da carne durante o procedimento de abate. Dentre as etapas de abate que mais envolvem risco de contaminação por Salmonella são a evisceração e o toalete, assim como a escaldagem e a divisão da carcaça (THORBERG e ENGVALL, 2001).

Os reservatórios de Staphylococcus aureus são os animais e o homem, sendo que para este a cavidade nasal é seu principal habitat e, a partir deste foco, atingem tanto a epiderme e feridas, como o ar, a água, solo e qualquer superfície ou objeto que tenha entrado em contato com o 
homem.Assim, os portadores nasais e os manipuladores de alimentos infectados por S. aureus são importantes fontes de contaminação dos alimentos (FRANCO e LANDGRAF,1996). Para Schraft et al. (1992), a Salmonella e o S. aureus em plantas de processamento de carnes são identificados nas mãos de manipuladores, sobre as superfícies de trabalho e equipamentos demonstrando a facilidade de ocorrência de contaminação cruzada entre carcaças, evidenciando a importância da higiene no ambiente de abate.

Partindo desse contexto, o presente estudo objetiva avaliar as condições higiênicosanitárias de carcaças, ambiente, manipuladores e produtos durante o abate e produção, através de análises microbiológicas em frigorífico que abate suínos e fabrica embutidos no estado do Paraná.

\section{Material e métodos}

Para a realização do presente trabalho foi avaliado um intervalo de cinco horas de abate em um estabelecimento classificado como matadouro-frigorífico de suínos e fábrica de conservas, que abate em torno de duzentos suínos/dia, sob o Serviço de Inspeção Estadual (SIP), no Estado do Paraná. Direcionou-se o número de amostras coletadas de acordo com o fluxo do abate no estabelecimento, levando em consideração o seu fluxograma, o tempo necessário para a coleta em cada ponto na linha de abate.

Foram coletadas amostras de três carcaças da região do lombo em uma área de $100 \mathrm{~cm}^{2}$ $(10 \mathrm{~cm} \times 10 \mathrm{~cm})$ através do método de $s w a b$ o qual se baseia na retirada da unidade analítica através da técnica do esfregaço de superfície segundo Silva (2007). A coleta foi realizada nas etapas de pré abate; após depilação; após evisceração; antes e pós lavagem, sendo as duas últimas coletadas da área interna e externa da carcaça, perfazendo 21 amostras.

Para verificar a contaminação do ambiente foram coletadas amostras utilizando o mesmo método e a mesma área determinada para carcaças. Os pontos selecionados para coleta foram: parede da área de sangria, depiladeira, mesa de evisceração, parede da câmara fria, mesa de fabricação de embutidos e $50 \mathrm{ml}$ de água de tanque de escaldagem.

Também foram coletadas amostras de mãos de dois manipuladores os quais trabalham na fabricação $100 \mathrm{~g}$ de dois embutidos, sendo um cozido e um cru.

Os materiais coletados foram transportados sob refrigeração e analisados no Laboratório de Microbiologia da UTFPR, onde foi feita a determinação do número mais provável (NMP) de coliformes totais, fecais (Escherichia coli), contagem padrão de microrganismos aeróbios mesófilos, estritos ou facultativos viáveis, contagem de Staphylococcus spp e avaliação da presença de Salmonella spp seguindo a metodologia descrita por Vanderzant e Splittstooesser (1992). Os resultados foram expressos em $\mathrm{mL}$, para a conversão dos resultados de $\mathrm{cm}^{2}$ para $\mathrm{mL}$ utilizou-se a seguinte fórmula $\mathrm{cm}^{2}=\mathrm{ml} / 10$. 


\section{Resultados e discussão}

Parte das amostras avaliadas apresentou contaminação por coliformes fecais, totais, mesófilos, Salmonella e Staphylococcus (Tabela 1), o grau de contaminação, no entanto, para a maioria das amostras, manteve-se dentro dos limites estabelecidos pela legislação.

Tabela 1- Número mais provável de coliformes totais e fecais, presença de salmonela e contagem de mesófilos aeróbios e Staphylococcus spp em carcaças, ambiente e produtos em frigorífico de suínos.

\begin{tabular}{|c|c|c|c|c|c|}
\hline Amostra & $\begin{array}{l}\text { Coliformes } \\
\text { Totais } \\
\text { NMP*/ml }\end{array}$ & $\begin{array}{l}\text { Coliformes } \\
\text { Fecais } \\
\text { NMP } * / m l\end{array}$ & $\begin{array}{c}\text { Salmonella } \\
\text { spp. } \\
\text { Presença } \\
\text { em 25g. }\end{array}$ & $\begin{array}{c}\text { Staphylococcus } \\
\text { UFC } * / m l\end{array}$ & $\begin{array}{c}\text { Mesófilos } \\
\text { aeróbios } \\
\text { UFC } * / \mathbf{m l}\end{array}$ \\
\hline Antes do abate & $<30$ & $<30$ & Ausente & $1,7 \times 10^{1}$ & $5,3 \times 10^{2}$ \\
\hline Pós depilação & $1,2 \times 10^{2}$ & $<30$ & Ausente & $2,4 \times 10^{2}$ & $2,2 \times 10^{2}$ \\
\hline Pós evisceração & $3,0 \times 10^{3}$ & $<30$ & Ausente & $9,3 \times 10^{2}$ & $5,1 \times 10^{2}$ \\
\hline $\begin{array}{c}\text { Antes lavagem } \\
\text { interna }\end{array}$ & $2,1 \times 10^{2}$ & $<30$ & Ausente & $2,5 \times 10^{2}$ & $2,0 \times 10^{2}$ \\
\hline $\begin{array}{c}\text { Antes lavagem } \\
\text { externa }\end{array}$ & $1,2 \times 10^{2}$ & $1,0 \times 10^{1}$ & Ausente & $2,0 \times 10^{2}$ & $2,0 \times 10^{2}$ \\
\hline $\begin{array}{l}\text { Pós lavagem } \\
\text { interna }\end{array}$ & $1,0 \times 10^{2}$ & $1,0 \times 10^{2}$ & Ausente & $3,0 \times 10^{2}$ & $4,1 \times 10^{2}$ \\
\hline $\begin{array}{c}\text { Pós lavagem } \\
\text { externa }\end{array}$ & $1,0 \times 10^{2}$ & $<30$ & Ausente & $1,5 \times 10^{2}$ & $1,4 \times 10^{2}$ \\
\hline Depiladeira & $3,8 \times 10^{2}$ & $2,2 \times 10^{1}$ & Ausente & $2,1 \times 10^{2}$ & $2,8 \times 10^{2}$ \\
\hline Cutter & $<30$ & $<30$ & Ausente & $1,1 \times 10^{2}$ & $6,0 \times 10^{2}$ \\
\hline Parede Sangria & $1,2 \times 10^{2}$ & $0,6 \times 10^{1}$ & Ausente & $0,5 \times 10^{2}$ & $3,9 \times 10^{2}$ \\
\hline $\begin{array}{c}\text { Mão } \\
\text { Manipulador }\end{array}$ & $<30$ & $<30$ & Ausente & $<1,0 \times 10^{0}$ & $<1,0 \times 10^{0}$ \\
\hline Mesa evisceração & $7,5 \times 10^{3}$ & $6,2 \times 10^{3}$ & Presente & $3,0 \times 10^{2}$ & $8,8 \times 10^{2}$ \\
\hline Mesa embutidos & $2,5 \times 10^{2}$ & $<30$ & Ausente & $1,8 \times 10^{2}$ & $0,9 \times 10^{2}$ \\
\hline Salsichão & $<30$ & $<30$ & Ausente & $0,4 \times 10^{2}$ & $<1,0 \times 10^{0}$ \\
\hline Lingüiça frescal & $1,2 \times 10^{1}$ & $<30$ & Ausente & $1,0 \times 10^{2}$ & $0,3 \times 10^{2}$ \\
\hline $\begin{array}{c}\text { Água de entrada } \\
\text { Tanque } \\
\text { escaldagem }\end{array}$ & $2,6 \times 10^{2}$ & $1,0 \times 10^{2}$ & Ausente & $5,4 \times 10^{2}$ & $6,3 \times 10^{2}$ \\
\hline $\begin{array}{l}\text { Água de saída } \\
\text { Tanque } \\
\text { escalgagem }\end{array}$ & $2,0 \times 10^{2}$ & $1,2 \times 10^{2}$ & Ausente & $4,2 \times 10^{2}$ & $5,5 \times 10^{2}$ \\
\hline
\end{tabular}

A carga microbiana presente no couro do animal pode exceder a $10^{9} \mathrm{UFC} / \mathrm{cm}^{2}$, contaminando a carcaça nas etapas iniciais do abate, por isto a importância da higiene do animal ante-mortem (TERRA e FRIES, 2001). Como forma de minimizar esta carga a legislação recomenda que os animais recebam um banho de aspersão durante três minutos na rampa de acesso ou corredor de matança. Conclui-se que o processo de higienização do animal pré-abate foi eficiente, pois a microbiota presente no couro dos animais apresentou valores relativamente baixo como mostra a tabela.

Observa- se que a quantidade de Coliformes totais, Staphylococcus $s p$. e Mesófios aeróbios, teve um aumento significativo entre a etapa da depilação e evisceração. A quantidade de Coliformes totais podem ter aumentado devido a um possível extravasamento de conteúdo visceral 
durante a etapa de evisceração. É importante que o funcionário responsável por esta etapa seja bem treinado para que as vísceras sejam retiradas por inteiro e evitar a ocorrência de perfuração do intestino do animal. Já o aumento de Staphylococcus sp. e Mesófilos aeróbios nesta mesma etapa pode ter sido ocasionado por contaminação cruzada advinda da manipulação dos funcionários, da depiladeira, da água do tanque de escaldagem e mesa de evisceração, sendo que os três últimos apresentaram carga microbiana significativa. Conforme TERRA e FRIES (2001), inevitavelmente a carcaça entra em contato com o couro, patas, pêlos, utensílios (facas), equipamentos, manipuladores (uniformes), água de lavagem e com o ar do abatedouro. Os equipamentos devem ser sanitizados eficientemente e os uniformes bem higienizados assim como a saúde dos manipuladores deve ser controlada. Observando os dados da tabela constatou-se que a etapa de evisceração é um ponto crítico de controle, pois este processo ocasionou um aumento significativo da carga microbiana.

A presença de microorganismos na carcaça diminuiu após a lavagem externa, porém aumentou para Coliformes fecais e Mesófilos aeróbios pós lavagem interna, indicando que o processo de lavagem desta área foi ineficiente, disseminando a contaminação, este fato pode ter sido decorrente do acúmulo de umidade na superfície, aliado a temperatura de pré-refrigeração ocasionando a proliferação de microrganismos.

A água do tanque de escaldagem apresentou pequena diferença na contagem de coliformes totais e fecais (NMP), Staphylococcus e mesófilos para as amostras coletadas no início e no final do processo, sendo que a menor contaminação foi para as amostras da última coleta, estes resultados possivelmente devem-se ao tempo de exposição dos microrganismos à temperatura elevada $\left(62^{0} \mathrm{C}\right)$ durante o processo de escaldagem, ocasionando a redução na carga microbiana devido à morte térmica dos microrganismos. Para ambas as amostras não foram verificadas a presença de Salmonella spp.

Com relação ao processo de fabricação de embutidos, após avaliar o manipulador, o ambiente e o produto, verificou-se que as mãos dos manipuladores encontraram-se em boas condições higiênicas, porém o cutter e a mesa de embutidos apresentaram maior carga microbiana. Este fato pode ter acarretado a contaminação da lingüiça frescal, sendo esta abaixo dos níveis estabelecidos pela legislação.

A legislação estabelece uma quantidade máxima de $10^{4}$ para coliformes termotolerantes não limitando para coliformes totais. Porém o índice de coliformes totais é utilizado para avaliar as condições higiênicas na qual este alimento foi produzido ou armazenado (DELAZARI, 1998). As condições higiênico-sanitárias do ambiente e manipulador do alimento, a temperatura de armazenagem, a higiene e conservação dos utensílios e equipamentos são pontos críticos e de risco para a qualidade da carne, embora estes pré-requisitos não sejam observados em muitos pontos de comercialização, especialmente as feiras livres. 
A legislação Brasileira estabelece o padrão de ausência de Salmonella em $25 \mathrm{~g}$ de produto (BRASIL, 2001). As carcaças analisadas não apresentaram presença de Salmonella, embora na mesa de evisceração tenha sido evidenciada a presença da mesma, a contaminação por Salmonella, no entanto, é bastante incidente em carcaças de diversos animais de abate, levantamentos em diferentes países apontam para a contaminação de 30 a 50\% das carcaças de frango congeladas ou refrigeradas com Salmonella (SILVA, 2004). No Brasil há relatos de contaminação por Salmonella em frangos e seus derivados variando de 9,15 a 86,7\% (CARVALHO e CORTEZ, 2005). A presença de Salmonella no trato intestinal pode ser decorrente de falhas no processo pré-abate, como pouco tempo de jejum dos animais, aliado ao estresse.

Segundo ROÇA e SERRANO (1995), a deterioração da carne tem seu início quando as contagens estão na faixa de $10^{6} \mathrm{UFC} / \mathrm{g}$, com descoloração da superfície. Entre $10^{7}$ a $10^{8} \mathrm{UFC} / \mathrm{g}$, surgem odores estranhos; entre $10^{8}$ a $10^{9} \mathrm{UFC} / \mathrm{g}$, ocorrem alterações indesejáveis de sabor; e em contagens por volta de $10^{9} \mathrm{UFC} / \mathrm{g}$, aparece o limo superficial.

Segundo ICSMF (1984) e EVANGELISTA (2001), fazem parte do grupo coliforme os seguintes gêneros pertencentes à família Enterobacteriaceae: Escherichia coli, Enterobacter, Klebsiella e Citrobacter. Ainda de acordo com EVANGELISTA (2001), o principal representante dos coliformes fecais é o gênero Escherichia, constituído por bactérias em forma de bastonete reto, móveis ou imóveis, Gram-negativas, algumas cepas dotadas de grande termorresistência e, por fermentação, formam gases e água.

ROÇA (2004) afirma que a contaminação pode ocorrer em todas as operações de abate, armazenamento e distribuição, e sua intensidade depende da eficiência das medidas higiênicas adotadas. O autor citado deixa também evidente que operações unitárias, realizadas de forma inadequada, podem justificar a presença do pico decorrente dos resultados de mesófilos encontrados na segunda repetição, para os grupos 1 e 2 do presente estudo.

Segundo GIL (2000), quando o número de bactérias mesófilas, na superfície de carcaças de bovinos e pequenos ruminantes, é superior a $105 / \mathrm{cm}^{2}$, o abate ocorreu em más condições de higiene.

A Portaria no 451/97, do Ministério da Saúde (BRASIL, 1997), estabelece como padrão para crustáceos, moluscos e produtos cárneos, com relação ao Staphylococcus, a contagem de $10^{3}$ $\mathrm{UFC} / \mathrm{g}$.

A presença de Staphylococcus aureus, em carcaças bovinas quentes ou refrigeradas, indica contaminação procedente das vias orais, nasais e pele dos manipuladores dos alimentos. Indica também materiais e equipamentos mal higienizados e matéria - prima animal contaminada (ELLIOTT et al., 1983).

Apesar dos dados avaliados não representarem uma contaminação microbiana efetiva, verificou-se a necessidade da implantação de um programa de Gestão da Qualidade com 
monitoramento de todas as etapas desde o recebimento da matéria prima até obtenção do produto final. Todas estas etapas devem seguir Procedimentos operacionais padronizados e os funcionários devem receber treinamento constante relativo às Boas Práticas de Fabricação, além de supervisionadas por um responsável do controle de qualidade.

\title{
4 Conclusão
}

A partir dos resultados obtidos no presente estudo conclui-se que o estabelecimento avaliado encontrou-se em condições higiênico-sanitárias satisfatórias, porém existe a necessidade de implantação de um programa de Gestão da Qualidade para reduzir a carga microbiana e principalmente contaminação cruzada.

\begin{abstract}
Meat products are strong backers of pathogenic bacteria, thus it is important to monitor the entire production process to ensure the microbiological quality of the final product. This study aimed investigates the hygienic and sanitary condition of a refrigerator slaughterhouse and built factory in Paraná. For this purpose, were assessed three pig carcasses in the loin region, using the swab samples of pre slaughter stage, after shave and evisceration and before and after washing, being the last three samples collected from indoor and outdoor of the carcasses. To assess hygiene samples of the environmental conditions were collected from the bleed area wall, epilator and evisceration table, built table manufacture and $50 \mathrm{ml}$ of the scald tank water. Samples were collected from the hands of two manufacturing workers and $100 \mathrm{~g}$ of two built, one being cooked and raw. The collected materials were transported and analyzed, to determine the most probable number (MPN) of total and fecal coliform (Escherichia coli), aerobic mesophilic bacterial counts, strict or facultative viable, Staphylococcus count and assessment of Salmonella spp. Some samples showed fecal and total coliforms, mesophilic, Salmonella and Staphylococcus contamination, although the degree of contamination for the majority of the samples remained within the limits set by law.
\end{abstract}

Key-words: contamination, swine carcasse, hygienic.

\section{Referências}

ABIPECS- Associação Brasileira da Indústria Produtora Exportadora de Carne Suína. Principais destinos da carne suína Brasileira- jan/abr 2011. Disponível em: < http://www.abipecs.org.br/pt/estatisticas/mercadoexterno/destinos.html>. Acesso em: 04 abr. 2011.

BESSA, M. C.; COSTA, M.; CARDOSO, M. Prevalência de Salmonella sp em suínos abatidos em frigoríficos sob inspeção federal no Rio Grande do Sul. Pesquisa Veterinária Brasileira, v. 24, n. 2, p. 80-84, 2004.

BEZZERA, W. I; MARTINS, T. D. D. Análise dos Pontos Críticos em uma unidade frigorífica de abate de suínos em Igarassu-PE. 3a jornada Nacional da Agroindústria.Bananeiras, Paraíba, 2008.

BORCH, E.; NESBASKKEN, T.; CHRISTEN, H. Harzard identification in swine slaughter with respect to foodborn bacteria. International Journal of Food Microbiology,v.30. p. 9-25, 1996. DOI: 10.1016/0168-1605(96)00988-9

BRASIL. Agência nacional de vigilância sanitária. Resolução ${ }^{\circ} 12$, de 2 de janeiro de 2001 . Regulamento técnico sobre os padrões microbiológicos para alimentos. 2001. 
BRASIL. Portaria n.o 451/97, de 22 de setembro de 1997. Aprova padrões microbiológicos para produtos alimentícios expostos à venda ou de alguma forma destinados ao consumo. Diário Oficial [da] República Federativa do Brasil, Ministério da Saúde, Brasília, DF, Seção 1. p. 21011-21012..

CAPITA, R.; ALONSO-CALLETA, C.; GRACIA- FERNANDEZ, M.C. et.al. Aspectos de intés em la calidad microbiológica de la carne de pollo. Eurocarne, v.9. n.73, p.73-86,1999.

CARMO, G. M. I., OLIVEIRA, A. A., DIMECH, C. P., SANTOS, D. A., ALMEIDA, M. G., BERTO, L. H., ALVES, R. M. S. \& CARMO, E. H. Vigilância epidemiológica das doenças transmitidas por alimentos no Brasil, $1999-2004$. Boletim Eletrônico Epidemiológico. v.6, p. 1-7, 2005.

CARVALHO, A.C.S.B.; CORTEZ, A.L.L. Salmonella spp em carcaças, carne mecanicamente separada, lingüiças e cortes comerciais em frango. Ciência Rural, v.35, n.6, p.1465-1468, 2005. DOI: 10.1590/S0103-84782005000600040

CORTEZ, A.L.L. Indicadores de qualidade higiênico-sanitária em lingüiça frescal comercializada no Município de Jaboticabal-SP. 2003. 42f. Dissertação (Mestrado) - Universidade Estadual Paulista, Faculdade de Ciências Agrárias e Veterinárias, Jaboticabal, 2003.

DELAZARI, I. Aspectos microbiológicos ligados a segurança e qualidade da carcaça de aves. In: Semana Acadêmica Veterinária, 8, Anais..., São Paulo. p.71-77. 1998.

EVANGELISTA, J. Tecnologia de alimentos. 2. ed. São Paulo: Editora Atheneu, 2001. 652p.

FRANCO,B.D.G.; LANDGRAF, M. Microbiologia dos Alimentos. São Paulo: Atheneu, SP. p 43-45, 1996.

GIL, J. A. S. I. Manual de inspeção sanitária de carnes. 2. ed. Lisboa: Fundação Calouste Gulbenkian, 2000.485 p.

HUGAS, M. Bacteriogenics lactic acid bactéria for the biopreservation of meat and products. Meat Science. V. 49, p. 139-150, 1998. DOI: 10.1016/S0309-1740(98)90044-4

ICMSF - Internacional Commission on Microbiological Specifications for Foods. Microrganismos de los alimentos: técnicas de análisis microbiológico. Zaragoza: Acribia, 1984. 431p.

ICMSF- Internacional Commission on Microbiological Specifications for Foods. APPCC na qualidade e segurança microbiológica de alimentos. São Paulo: Varela, 1997, 377p.

LIMA, A. W. O; SOUSA, C. P. Infecções e intoxicações alimentares. In: Aspectos da ciência e tecnologia de alimentos. 1 ed. João Pessoa, PB: Nova Idéia , v. 1, p. 175-199, 2002.

MARRA, K. N. Dinâmica microbiana da sala de desossa em um matadouro- frigorífico de Goiânia- GO, durante a jornada de trabalho. 2009. 68f. Dissertação (Mestrado em Ciência Animal)- Escola de Veterinária, Universidade Federal de Goiás, Goiânia, 2009.

MATSUBARA, E.N. Condição higiênico - sanitária de meias carcaças de suínos após o abate e depois do resfriamento e análise de utilização de Lista de Verificação para avaliar boas práticas no abate de suínos.152p. Dissertação (Mestrado) Universidade de São Paulo, Faculdade de Zootecnia, São Paulo, 2005.

OMS. Organização Mundial da Saúde. Emerging foodborne disease. Fact Sheet, n.124, revised January 2002. Disponível em: http://www.who.int/inffs/in/fact124.html. Acesso em: 20 de agosto de 2010.

ROÇA, R. O; SERRANO; A. M. Abate de bovinos: alterações microbianas da carcaça. Higiene Alimentar, v. 9, n. 35, p. 8-13. 1995.

ROÇA, R. O. Microbiologia da carne. UNESP, Campus de Botucatu, 2004. Disponível em: http://www.fca.unesp.br/outros/tcarne/tecarne.htm\#s5. Acesso em: 12 set. 2010.

SCHRAFT, H.; KLEINLEIN, N.; UNTERMANN, F. Contamination of hindquarters with Staphylococcus aureus. International Journal of Food Microbiology, v. 15, n. 1-2, p.191-194,1992. DOI: 10.1016/0168-1605(92)90148-V

SEIXAS, F. N., TOCHETTO, R., FERRAZ, S. M. Presença de Salmonella sp. em carcaças suínas amostradas em diferentes pontos da linha de processamento. Ciência e Animal Brasileira, v.10, n.2, p.634-640, 2009. 
SILVA, M . C. D. Salmonella sp em ovos e carcaças de frangos "in natura" comercializados em Maceió -AL. Higiene alimentar, v.18, n.121, p.80-84, 2004.

SILVA, N ; JUNQUEIRA, V. C. A.; SILVEIRA, N.F.A. Manual de Métodos de Análise Microbiológica de Alimentos. 3 ed. São Paulo: Varela, 2007.

TERRA, N. N.; FRIES, L. L. M. A qualidade da carne suína e sua industrialização. 1a Conferência Internacional Virtual sobre Qualidade de Carne Suína, Embrapa, Concórdia, Santa Catarina, 2001p.147-151.

THORBERG, B. M.; ENGVALL, A. Incidence of Salmonella in slaughterhouse. Journal Food Protection. v. 64, n. 4, p. 542-545, 2001.

VANDERZANT, C; SPLITTSTOOSSER, R. D. F. Compendium of methods for the microbiological examination of foods. 15 ed.; Washington, DC. APHA, 1992. 1219p.

Trabalho selecionado para apresentação oral durante a VIII SETAL- Semana de Tecnologia de Alimentos- Câmpus Ponta Grossa- Universidade Tecnológica Federal do Paraná- 01 a 03 de junho de 2011. Suplemento especial da RBTA. 